\title{
Effects of a gestational weight gain restriction program for obese women: Sibling pairs weight development during the first five years of life
}

Ing-Marie Claesson, Ann J osefsson, Elisabeth Olhager, Carin Oldin and Gunilla Sydsjö

The self-archived postprint version of this journal article is available at Linköping University Institutional Repository (DiVA):

http:// urn.kb.se/ resolve?urn=urn:nbn:se:liu:diva-152073

N.B.: When citing this work, cite the original publication.

Claesson, I., J osefsson, A., Olhager, E., Oldin, C., Sydsjö, G., (2018), Effects of a gestational weight gain restriction program for obese women: Sibling pairs weight development during the first five years of life, Sexual \& Reproductive HealthCare, 17, 65-74. https:// doi.org/ 10.1016/j.srhc.2018.07.003

Original publication available at:

https:// doi.org/ 10.1016/j.srhc.2018.07.003

Copyright: Elsevier (12 months)

http:// www.elsevier.com/

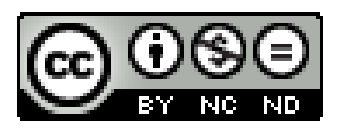


Effects of a Gestational Weight Gain Restriction Program for Obese Women: Sibling Pairs’ Weight Development during the First Five Years of Life

Ing-Marie Claesson, RNM $\mathrm{PhD}^{1}$, Ann Josefsson, $\mathrm{MD}, \mathrm{PhD}^{1}$, Elisabeth Olhager, $\mathrm{MD}, \mathrm{PhD}^{2}$, Carin Oldin, $\mathrm{MD}^{3}$, Gunilla Sydsjö, $\mathrm{PhD}^{1}$

${ }^{1}$ Department of Obstetrics and Gynaecology, and Department of Clinical and Experimental Medicine, Linköping University, Linköping, Sweden

E-mail: Ing-Marie.claesson@liu.se Ann.Josefsson@regionostergotland.se

Gunilla.Sydsjo@regionostergotland.se

${ }^{2}$ Department of Clinical Sciences and Department of Paediatrics, Lund University, Sweden E-mail: Elisabeth.Olhager@skane.se

${ }^{3}$ Child Health Services, Public health and health care, Region Jönköping County, Jönköping, Sweden

E-mail: Carin.Oldin@rjl.se

Acknowledgements: We thank Marie Bladh, statistician, PhD, for statistical advisory

Declarations of interest: none 


\section{Correspondence:}

Ing-Marie Claesson

Division of Obstetrics and Gynecology

Department of Clinical and Experimental Medicine

Faculty of Medicine and Health Sciences

Linköping University

SE - 58183 Linköping, Sweden

Tel. +46101032923

Fax: +4613148156

Email: Ing-Marie.Claesson@liu.se 


\begin{abstract}
Objectives: Successful gestational weight gain (GWG) restriction programs for obese (Body Mass Index (BMI) $\geq 30 \mathrm{~kg} / \mathrm{m}^{2}$ ) pregnant women, have not, so far, shown convincing effects on infant's weight development. An intervention starting during the pregnancy might be too late and a pre-conceptional life style change may be preferable. Thus, the aim of this study was to follow children born to mothers who had participated in a weight gain restriction program during pregnancy, and make comparisons with their younger siblings.
\end{abstract}

Study design and main outcome measures: An extended analysis of 262 children belonging to an intervention group and a control group. The effects of BMI at five years of age and weight-for-length/height development from two months of age until five years of age were assessed.

Results: In the intervention group there was a difference in BMI at five years of age, between index boys and their younger sisters $(\mathrm{p}=0.016)$. Mean BMI was lower among the boys compared with their younger female siblings. Regarding maternal GWG or the Swedish national reference data there was no difference between the index children and their younger siblings within the intervention or control groups or between younger siblings in the two groups.

Conclusions: Maternal pre-conceptional lifestyle change may have a positive effect on the child's weight development during the five first years of age. However, the effect of participation in an extensive GWG restriction program when it comes to the impact on the offspring's weight development is still unclear and further research is required.

Keywords: obesity; weight development; sibling; follow-up study 


\section{List of abbreviations}

$\mathrm{BMI}=$ Body Mass Index

GWG $=$ Gestational Weight Gain

$\mathrm{WL} / \mathrm{H}=$ Weight-for-Length/Height

$\mathrm{ANC}=$ Antenatal Care Clinic

CWC $=$ Child Welfare Center

$\mathrm{ZWL} / \mathrm{H}=$ standard score (z-score) of Weight-for-Length/Height

ZBMI = standard score (z-score) of Body Mass Index 


\section{Introduction}

There is evidence that maternal obesity and excessive gestational weight gain may lead to childhood obesity [1-3], which in Sweden have been estimated to 3-5 \% [4]. Intervention studies during pregnancy, aiming to change behavior concerning energy intake and physical activity and thereby restrict the weight gain and decrease adverse outcomes for both mother and child, have been carried out with divergent results [5, 6]. Follow-up studies of the effect of a gestational intervention program on the offspring during childhood have also shown conflicting results [7-13]. In recent years, the question of whether it is too late to begin a life style intervention during pregnancy has arisen and the need for a pre-conceptional change has been suggested $[14,15]$.

We have previously shown that a gestational weight gain (GWG) restriction program is effective $[16,17]$ and it seems that the positive effect on the woman's weight development remains up to six years after the intervention [18]. We could not detect any differences in the offspring's weight development during the first five years of life, between children whose mothers belonged to the intervention group or the control group [19]. In an extended analysis we investigated the outcome of a GWG restriction program for obese pregnant women on younger siblings of the index children in order to investigate the potential impact of preconceptional behavior change. We compared sibling pairs and estimated the effect of BMI at five years of age and weight-for-length/height $(\mathrm{WL} / \mathrm{H})$ development from two months of age until five years of age. 


\section{Methods}

The study groups comprised index children and their younger siblings whose mothers participated in an intervention study during 2004-2006 at the antenatal care clinic (ANC) in Linköping. A control group of obese pregnant women was recruited from the ANCs in two nearby cities. The siblings were born within five years after the "index child" (i.e. the pregnancy when the mother participated in the intervention study). The original study and the follow-up studies are described elsewhere and are summarized briefly below [16-19]. The intervention program consisted of individual weekly visits with a specially trained midwife during pregnancy and every six months during the first two years after childbirth. The purpose of the visits was to change behaviors regarding nutrition and physical activity. The participants were also invited to join aqua aerobic classes especially designed for obese women. A total of 155 women (67.4\%) completed the intervention program. The control group consisted of 193(50.1\%) pregnant obese women who followed the routine program at the ANCs. All the women were recruited and included in the study in early pregnancy, i.e. before gestational week 15. Follow-up studies concerning the weight development of the women were undertaken two and six years after the index pregnancy. The weight development of all children was followed up at five years of age.

In Sweden all families are offered preventive health care for their children throughout childhood and youth. The preventive health care program is free of charge and reaches almost $100 \%$ of all children [20]. At the Child Welfare Center (CWC) children are advised to attend the regular health program (weight and length/height development, physical health, immunizations, cognitive and linguistic development).

\section{Subjects}

A description of the population in the original and follow-up studies is displayed in Figure 1. All mothers ( $\mathrm{n}=124)$ from the original study (the index pregnancy) who within five years 
gave birth to additional children were sent a letter with information about the follow-up of their children. Parents of 71 children belonging to the intervention group agreed to participate in the follow-up study, whereas one family refrained. Seventy-one children from the control group were eligible but one child was excluded because of illness (spina bifida and hydrocephalus) and three families refrained from participation. Thus 64 index children and 71 younger siblings (98.6 \%) from the intervention group and 60 index children and 67 younger siblings (94.4\%) from the control group took part. The majority of the participators were full-siblings (97.2 \% in the intervention group and $98.5 \%$ in the control group). Maternal characteristics with respect to all children who participated in this follow-up study are displayed in Table 1. The information is based on data from the 6-years follow-up study [18].

\section{$\underline{\text { Data collection }}$}

Data were manually extracted from the records at the CWC by the main author (IMC): weight and height data at two, six, 12 and 18 months of age and at four and five years of age. Information about illness, disability, parental smoking habits and breastfeeding was also obtained. Children’s background characteristics were obtained from delivery and neonatal records. In Sweden these medical records are standardized for all care within specialty.

\section{$\underline{\text { Statistics }}$}

All analyses were performed using the IBM SPSS program, version 23.0 (IBM Corp., Armonk, NY, USA). Statistical significance was defined as (two-sided) $\mathrm{p} \leq 0.05$. Before analyzing the weight changes, the assumption of these variables being normally distributed was validated using the Kolmogorov-Smirnov test. This assumption was not confirmed. A Mann Whitney U-test was therefore used as the method of analysis on all continuous variables. Group differences were estimated by using a Pearson chi-square test and Fischer's 
Exact Test on categorical variables. To make a more comprehensive assessment of group differences, linear regressions were performed with BMI at five years of age as a dependent variable, while as independent variable we used birth weight. The size of the child was analyzed using weight and length/height. The value was converted to WL/H (e.g. weight/length or height) and its standard score (z-score) was used (ZWL/H). The child's BMI at five years of age was analyzed with respect to BMI reference values, expressed in mean and standard deviations, for Swedish children [21].

\section{Ethics}

Ethics approval and consent to participate: The study was performed in accordance with the Declaration of Helsinki of 1975, as revised in 2013 and approved by the Regional Ethical Review Board in Linköping, Sweden. Dnr. 2010/400-31. Ethical principles for studies were followed: All parents obtained written and oral information about the study. Written consent was obtained from all parents. All data have been treated confidentially. 


\section{Results}

Table 2 show child characteristics. Among the index children there were more children with macrosomia in the control group, compared with the intervention group $(p=0.038)$.

The index children's and their younger male or female siblings' BMI and its standard score of BMI (ZBMI) at five years of age and in relation to maternal GWG during the index pregnancy are displayed in Table 3a and Table 3b. Concerning the intervention group and irrespectively the women’s GWG during the index pregnancy, there was a significant difference between index boys and their younger sisters ( $p=0.013$ ) (Table 3a). Mean BMI was lower among the male index children compared with their younger female siblings. After adjusting for birth weight the significant difference remained $(\mathrm{p}=0.016)$. Furthermore, regarding the intervention group and women with GWG $<7 \mathrm{~kg}$ during the index pregnancy, there was a difference between index girls and their younger sisters ( $p=0.047)$ (Table 3b). The female index children had a higher mean BMI compared with their younger female siblings. After adjusting for birth weight the significant difference disappeared $(p=1.000)$. A sub-analysis between younger male siblings’ BMI and younger female siblings’ BMI in the two groups showed no differences (Table 4). The index children and their younger siblings' BMI at five years of age were also analyzed with respect to national reference data (Table 5). There was no significant difference in BMI between the children within the intervention or control groups. We also compared BMI according to reference values for Swedish children between younger male and female siblings in the intervention and control groups at five years of age and found no differences (Table 6). The distributions of standardized scores of WL/H among index children and their younger siblings in the intervention and control groups, from two months of age until five years of age, are displayed in Figure 2 and show no differences. 


\section{Discussion}

During recent years, the value of a pre-conceptional life style change has been discussed [14, 15]. In this extended analysis we therefore compared weight development and BMI among sibling pairs whose mothers participated in a weight gain restriction program during pregnancy. The results from our previous studies on weight indicate that the women in the intervention group might have undergone a lifestyle change, compared with the women in the control group [16-18]. These changes were not reflected in the index children's weight development or BMI during the first five years of age [19]. In the present study encompassing sibling pairs, born within five years after the mother's participation in the intervention program, there was a difference between the male index children and their younger female siblings in the intervention group. This result should be interpreted with caution. The sample size was small and there is also, according to Swedish reference value, a small difference in mean BMI between the genders, at five years of age boys had slightly higher mean BMI in comparison with girls [21]. In our study the relationship was the reverse. Furthermore, there was no difference concerning the distribution of BMI value among the 15 index boys and the 16 younger sisters (Table 5). However, as shown by Forsum et al. [22], BMI-based cut offs for overweight should be interpreted with caution. BMI is a poor predictor of the body fat content of individual subjects and may not effectively identify children with a high body fat content. BMI only explains a small proportion of the variation in body fat [22]. Despite the absence of significant differences, the majority of all children, irrespective of gender or group, had a BMI above the average range of Swedish reference data.

Terry et al. [23] investigated the relationship between pre- and postnatal factors and the body size at seven years of age. They observed among same-sex siblings that siblings with higher BMI at seven years of age were more likely to have a higher maternal pre-pregnancy BMI 
and GWG, a higher birth weight and an increased rate of weight gain during the first four years of age, than their siblings. In our study we found among different sex siblings that index children born after their mothers' participation in the weight gain restriction program, had, irrespectively of the mother’s GWG, lower BMI than siblings born within five years after the program.

A number of intervention studies have shown positive effects on maternal GWG, whereas the effect of avoiding adverse pregnancy and/or neonatal outcome is limited [24-26]. So far these intervention programs have started during pregnancy and mainly after the first trimester, i.e. long after the feto-placental components have been exposed to an unfavorable metabolic environment. To reduce adverse obesogenic mediated effects on pregnancy, improvements in the metabolic environment of obese women are required [27]. These improvements should ideally be initiated before the pregnancy and therefore the importance of and the possibility of a pre-pregnancy intervention or counselling may be an essential question. Also a recent Australian article [28] highlights both the need for research concerning an effective preconceptional intervention to achieve a healthy pregnancy and a favorable neonatal outcome for obese women, but also the difficulty in recruiting participants to a study. Non-pregnant women do not identify themselves as ‘pre-conception’ or as a high-risk group. They are predominantly healthy and therefore have little contact with the healthcare system [28]. In a retrospective study the effectiveness of pre-conceptional consults for obese women was investigated [29]. Despite the fact that there was widely documented discussion of potential obesity-related pregnancy complications, the consultations were ineffective in significantly affecting pre-pregnancy weight loss. On the other hand, Weisman et al. [30] showed in a preconceptional behavioral intervention that women who participated in the program and gave birth within 12-month follow-up period, had a significantly lower mean GWG compared with 
controls. However, when controlling for pre-pregnancy obesity, the intervention effect was no longer significant.

There are strengths as well as weaknesses in this study. To our knowledge, this follow-up study is the first to compare the weight development among sibling pairs whose mother participated in a weight gain restriction program. All data were collected from medical records, i.e. there is no self-reported data. Although there were few individuals in the subgroups, the total rate of participation in both the intervention and control groups was high. The lack of power is a weakness. However, the original study had a high power to detect difference in maternal GWG [16].

\section{Conclusions}

In conclusion, the effect of participation in an extensive gestational weight gain restriction program and its impact on the offspring is still unclear. BMI and WL/H do not differ between offspring born within five years after the mother's participation in the intervention. The challenge to perform an intervention program which provides positive results for both the woman well as for her offspring remain. Continuous studies on family intervention aiming to investigate how the life style of the parents affects offspring's diet, body size and weight development may bring more insights into this topic.

Acknowledgements: We thank Marie Bladh, statistician, PhD, for statistical advisor 
Funding: This study was supported by grants from The Health Research Council of the Southeast of Sweden and ALF, County Council of Östergötland 


\section{References}

1. Tie HT, Xia YY, Zeng YS, et al. Risk of childhood overweight or obesity associated with excessive weight gain during pregnancy: a meta-analysis. Arch Gynecol Obstet. 2014 Feb;289[2]:247-57.

2. Jin WY, Lv Y, Bao Y, et al. Independent and Combined Effects of Maternal Prepregnancy Body Mass Index and Gestational Weight Gain on Offspring Growth at 0-3 Years of Age. BioMed research international. 2016;2016:4720785.

3. Gaillard R, Felix JF, Duijts L, Jaddoe VW. Childhood consequences of maternal obesity and excessive weight gain during pregnancy. Acta Obstet Gynecol Scand. 2014 Nov;93[11]:10859.

4. Sweden, The National Board of Health and Welfare. Health care report 2009. Stockholm: Socialstyrelsen; 2010.

5. Agha M, Agha RA, Sandall J. Interventions to reduce and prevent obesity in pre-conceptual and pregnant women: a systematic review and meta-analysis. PLoS One. 2014;9[5]:e95132.

6. Poston L, Bell $\mathrm{R}$, Croker $\mathrm{H}$, et al. Effect of a behavioural intervention in obese pregnant women (the UPBEAT study): a multicentre, randomised controlled trial. The lancet Diabetes \& endocrinology. 2015 Oct;3[10]:767-77.

7. Mustila T, Raitanen J, Keskinen P, et al. Lifestyle counseling during pregnancy and offspring weight development until four years of age: follow-up study of a controlled trial. Journal of negative results in biomedicine. 2012;11:11.

8. Mustila T, Raitanen J, Keskinen $\mathrm{P}$, et al. Lifestyle counselling targeting infant's mother during the child's first year and offspring weight development until 4 years of age: a follow-up study of a cluster RCT. BMJ open. 2012;2[1]:e000624.

9. Mustila T, Raitanen J, Keskinen P, et al. Pragmatic controlled trial to prevent childhood obesity in maternity and child health care clinics: pregnancy and infant weight outcomes (the VACOPP Study). BMC Pediatr. 2013;13:80.

10. Tanvig M, Vinter CA, Jorgensen JS, et al. Effects of lifestyle intervention in pregnancy and anthropometrics at birth on offspring metabolic profile at 2.8 years - results from the Lifestyle in Pregnancy and Offspring (LiPO) study. J Clin Endocrinol Metab. 2014 Oct 24:jc20142675.

11. Vesco KK, Leo MC, Karanja N, et al. One-year postpartum outcomes following a weight management intervention in pregnant women with obesity. Obesity (Silver Spring). 2016 Oct;24[10]:2042-9.

12. Ronnberg AK, Hanson U, Nilsson K. Effects of an antenatal lifestyle intervention on offspring obesity - a 5-year follow-up of a randomized controlled trial. Acta Obstet Gynecol Scand. 2017 Sep;96[9]:1093-9.

13. Patel N, Godfrey KM, Pasupathy D, et al. Infant adiposity following a randomised controlled trial of a behavioural intervention in obese pregnancy. Int J Obes (Lond). 2017 Jul;41[7]:1018-26.

14. Fraser A, Tilling K, Macdonald-Wallis C, et al. Association of maternal weight gain in pregnancy with offspring obesity and metabolic and vascular traits in childhood. Circulation. 2010 Jun 15;121[23]:2557-64.

15. Berglund A, Lindmark G. Preconception health and care (PHC)-a strategy for improved maternal and child health. Upsala journal of medical sciences. 2016 Jun 20:1-6.

16. Claesson IM, Sydsjo G, Brynhildsen J, et al. Weight gain restriction for obese pregnant women: a case-control intervention study. BJOG. 2008 Jan;115[1]:44-50.

17. Claesson IM, Sydsjo G, Brynhildsen J, et al. Weight after childbirth: a 2-year follow-up of obese women in a weight-gain restriction program. Acta Obstet Gynecol Scand. 2010 Jan;90[1]:103-10. 
18. Claesson IM, Josefsson A, Sydsjo G. Weight six years after childbirth: a follow-up of obese women in a weight-gain restriction programmme. Midwifery. 2014 May;30[5]:506-11.

19. Claesson IM, Sydsjo G, Olhager E, et al. Effects of a Gestational Weight Gain Restriction Program for Obese Pregnant Women: Children's Weight Development during the First Five Years of Life. Childhood obesity. 2016 Jun;12[3]:162-70.

20. The Public Health Agency of Sweden. Available at: https://www.folkhalsomyndigheten.se/globalassets/statistikuppfoljning/vaccinationsstatistik/bvc/vaccinationsstatistik-barnhalsovarden-2014-riket.pdf Retrieved October 2017.

21. Karlberg J, Luo ZC, Albertsson-Wikland K. Body mass index reference values (mean and SD) for Swedish children. Acta Paediatr. 2001 Dec;90[12]:1427-34.

22. Forsum E, Flinke Carlsson E, Henriksson $\mathrm{H}$, et al. Total body fat content versus BMI in 4-yearold healthy Swedish children. Journal of obesity. 2013;2013:206715.

23. Terry MB, Wei Y, Esserman D, et al. Pre- and postnatal determinants of childhood body size: cohort and sibling analyses. Journal of developmental origins of health and disease. 2011 Apr;2[2]:99-111.

24. Thangaratinam S, Rogozinska E, Jolly K, et al. Effects of interventions in pregnancy on maternal weight and obstetric outcomes: meta-analysis of randomised evidence. BMJ. 2012 May 16;344:e2088.

25. Muktabhant B, Lawrie TA, Lumbiganon P, Laopaiboon M. Diet or exercise, or both, for preventing excessive weight gain in pregnancy. The Cochrane database of systematic reviews. 2015 Jun 15[6]:CD007145.

26. Dodd JM, Deussen AR, Mohamad I, et al. The effect of antenatal lifestyle advice for women who are overweight or obese on secondary measures of neonatal body composition: the LIMIT randomised trial. BJOG. 2016 Jan;123[2]:244-53.

27. Catalano PM, Shankar K. Obesity and pregnancy: mechanisms of short term and long term adverse consequences for mother and child. BMJ. 2017 Feb 8;356:j1.

28. Harrison CL, Skouteris H, Boyle J, Teede HJ. Preventing obesity across the preconception, pregnancy and postpartum cycle: Implementing research into practice. Midwifery. 2017 Jun 15;52:64-70.

29. Page CM, Ginsburg ES, Goldman RH, Zera CA. Preconception consultations with Maternal Fetal Medicine for obese women: a retrospective chart review. Fertility research and practice. 2017;3:3.

30. Weisman CS, Hillemeier MM, Downs DS, et al. Improving women's preconceptional health: long-term effects of the Strong Healthy Women behavior change intervention in the central Pennsylvania Women's Health Study. Women's health issues : official publication of the Jacobs Institute of Women's Health. 2011 Jul-Aug;21[4]:265-71. 


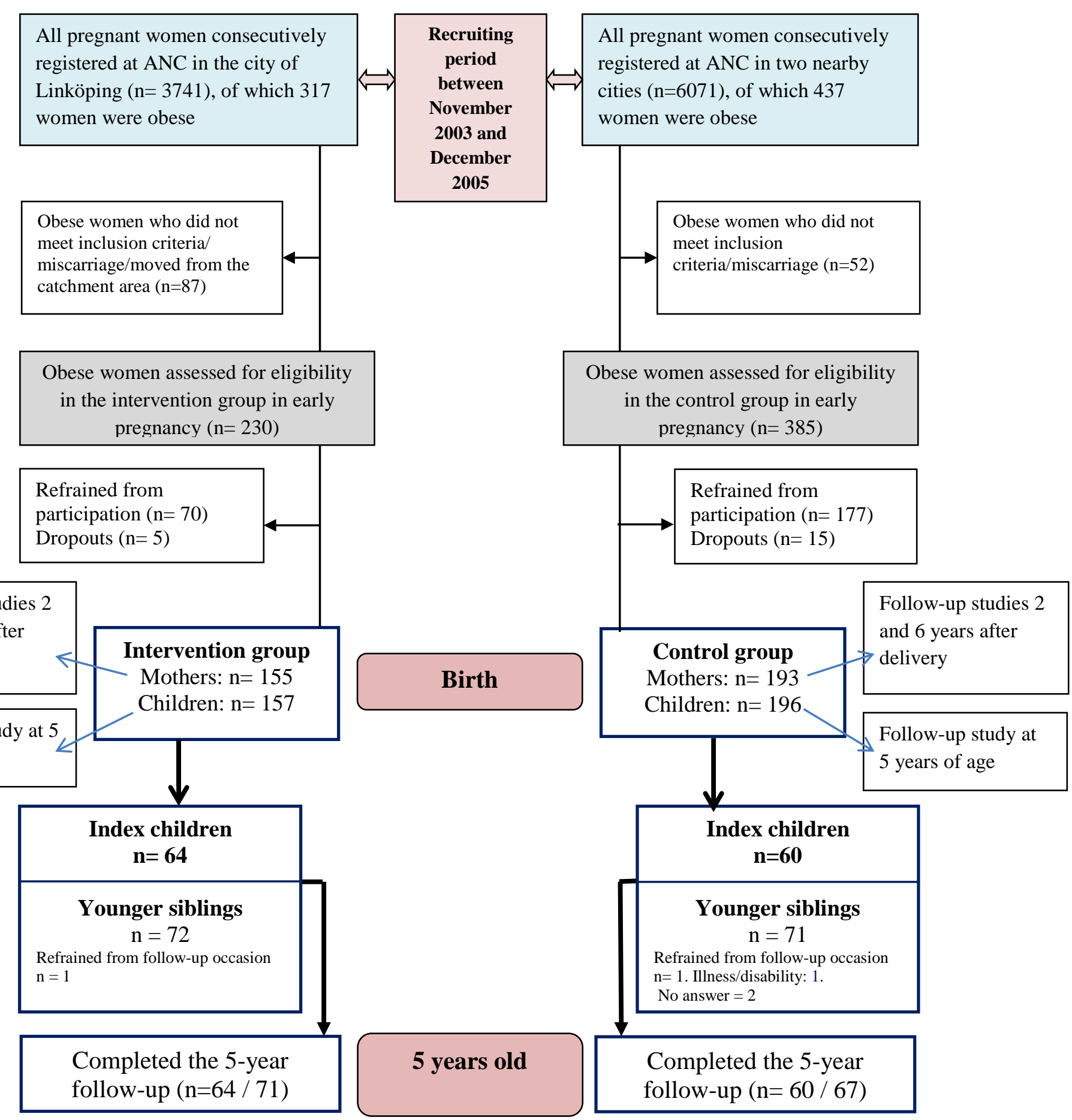

Figure1. Description of the population in the original- and follow-up studies 


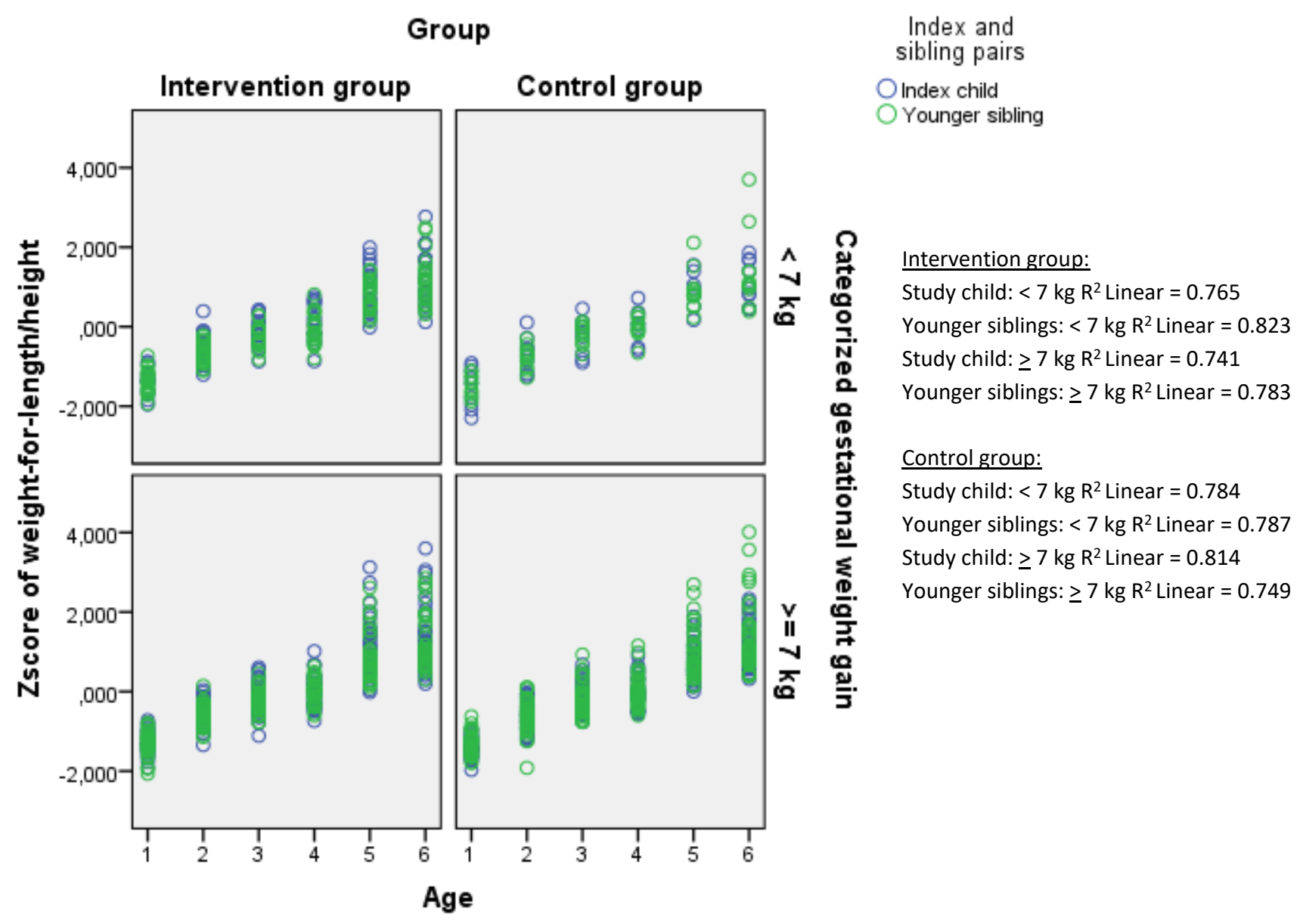

Figure 2. Distribution of standardized scores of weight-for-length/height from 2 months of age until 5 years of age among index children and their younger siblings in the interventionand control group 
Table 1. Maternal characteristics six years after the index pregnancy a

\begin{tabular}{|c|c|c|c|c|c|}
\hline & \multicolumn{2}{|c|}{$\begin{array}{l}\text { Intervention } \\
\text { group }\end{array}$} & \multicolumn{2}{|c|}{ Control group } & \multirow[b]{2}{*}{$p^{\mathrm{b}}$} \\
\hline & $\mathrm{n}$ & $\%$ & $\mathrm{n}$ & $\%$ & \\
\hline Age (mean, SD) & 64 & $\begin{array}{c}35.0 \\
(3.83)\end{array}$ & 60 & $\begin{array}{c}34.8 \\
(4.36)\end{array}$ & $0.652^{c}$ \\
\hline Parity & & & & & $0.640^{\mathrm{d}}$ \\
\hline Two children & 39 & 60.9 & 39 & 65.0 & \\
\hline Three children or more & 25 & 39.1 & 21 & 35.0 & \\
\hline Marital status & & & & & $0.624^{\mathrm{d}}$ \\
\hline Married / cohabiting with the child's father & 57 & 89.1 & 55 & 91.7 & \\
\hline Other family situation & 7 & 10.9 & 5 & 8.3 & \\
\hline Education level, year & & & & & $0.334^{\mathrm{d}}$ \\
\hline$<9$ & 1 & 1.5 & 4 & 6.7 & \\
\hline $10-12$ & 33 & 51.6 & 31 & 51.7 & \\
\hline$>12$ & 30 & 46.9 & 25 & 41.7 & \\
\hline Occupation & & & & & $0.838^{\mathrm{d}}$ \\
\hline Gainfully employed / parental leave / student & 58 & 90.6 & 55 & 91.7 & \\
\hline Not gainfully employed & 6 & 9.4 & 5 & 8.3 & \\
\hline Tobacco user & & & & & $0.371^{\mathrm{d}}$ \\
\hline No & 55 & 85.9 & 49 & 81.67 & \\
\hline Yes & 7 & 10.9 & 10 & 16.67 & \\
\hline No data available & 2 & 3.1 & 1 & 1.67 & \\
\hline $\begin{array}{l}\text { Weight change (kg) from early index pregnancy to six } \\
\text { years after child (irrespective gestational weight gain) }\end{array}$ & 62 & $\begin{array}{c}-4.7 \\
(11.76)\end{array}$ & 58 & $\begin{array}{c}-0.4 \\
(11.15)\end{array}$ & $0.029^{c}$ \\
\hline $\begin{array}{l}\text { Weight change (kg) from early index pregnancy to six } \\
\text { years after child (gestational weight gain }<7 \mathrm{~kg} \text { ) }\end{array}$ & 20 & $\begin{array}{c}-10.4 \\
(13.11) \\
\end{array}$ & 9 & $\begin{array}{c}-0.9 \\
(5.18)\end{array}$ & $0.018^{c}$ \\
\hline
\end{tabular}

${ }^{\text {a }}$ All values are given as frequencies unless otherwise stated

${ }^{\mathrm{b}}$ Missing data are not included in the analyses

${ }^{\mathrm{c}}$ Mann-Whitney U test

${ }^{\mathrm{d}}$ Pearson Chi-Square Test 
Table 2. Children (index and their younger siblings) characteristics in the intervention- and control group ${ }^{\mathrm{a}}$

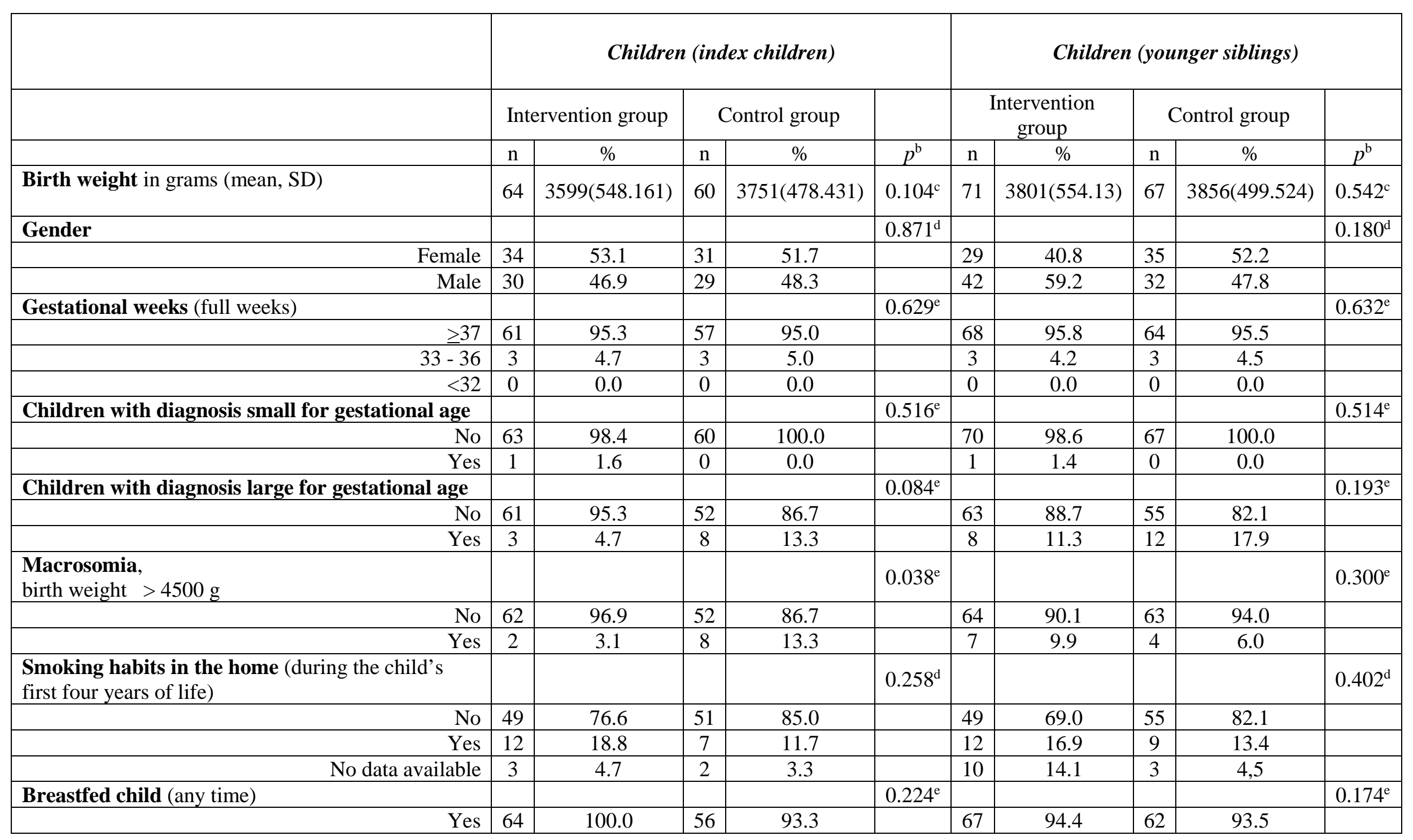




\begin{tabular}{|c|c|c|c|c|c|c|c|c|c|c|}
\hline No & 0 & 0.0 & 2 & 3.3 & & 1 & 1.4 & 4 & 6.0 & \\
\hline No data available & 0 & 0.0 & 2 & 3.3 & & 3 & 4.2 & 1 & 2.9 & \\
\hline Duration of total breastfeeding (month) & & & & & $0.511^{\mathrm{d}}$ & & & & & $0.323^{\mathrm{d}}$ \\
\hline$>12$ & 7 & 10.9 & 8 & 13.3 & & 8 & 11.3 & 8 & 11.9 & \\
\hline 6-11 & 29 & 45.3 & 24 & 40.0 & & 29 & 40.8 & 34 & 50.7 & \\
\hline $3-5$ & 13 & 20.3 & 14 & 23.3 & & 23 & 32.4 & 17 & 25.4 & \\
\hline$<3$ & 15 & 23.4 & 10 & 16.7 & & 7 & 9.9 & 3 & 4.5 & \\
\hline 0 & 0 & 0.0 & 2 & 3.3 & & 1 & 1.4 & 4 & 6.0 & \\
\hline No data available & 0 & 0.0 & 2 & 3.3 & & 3 & 4.2 & 1 & 1.5 & \\
\hline Duration of exclusive breastfeeding (months) & & & & & $0.986^{\mathrm{d}}$ & & & & & $0.790^{\mathrm{d}}$ \\
\hline $4-6$ & 35 & 54.7 & 31 & 51.7 & & 37 & 52.1 & 34 & 50.7 & \\
\hline $1-3$ & 11 & 17.2 & 9 & 15.0 & & 12 & 16.9 & 11 & 16.4 & \\
\hline$<1$ & 9 & 14.1 & 9 & 15.0 & & 7 & 9.9 & 5 & 7.5 & \\
\hline 0 & 9 & 14.1 & 9 & 15.0 & & 12 & 16.9 & 16 & 23.9 & \\
\hline No data available & 0 & 0.0 & 2 & 3.3 & & 3 & 4.2 & 1 & 1.5 & \\
\hline
\end{tabular}

a All values are given as frequencies unless otherwise stated

${ }^{\mathrm{b}}$ Missing data are not included in the analyses

${ }^{\mathrm{c}}$ Mann-Whitney U test

${ }^{\mathrm{d}}$ Pearson Chi-Square Test

e Fisher's Exact Test 
Table 3a. Body Mass Index (BMI) and standard score of Body Mass Index (ZBMI) for index boys and their younger siblings in the intervention- and control group at 5 years (y) of age and in relation to gestational weight gain (GWG) in the index pregnancy

\section{Intervention group}

\section{All children}

BMI at $5 \mathrm{y}$ of age

ZBMI at $5 \mathrm{y}$ of age

Boys

Children of mothers with $\mathrm{GWG} \geq 7 \mathrm{~kg}^{* *}$

BMI at 5 y of age

ZBMI at $5 \mathrm{y}$ of age

$\begin{array}{ccccc}10 & 17.6 & 2.706 & 11 & 16.0 \\ 10 & 0.511 & 1.453 & 11 & -0.367\end{array}$

Index child boy Younger sibling boy

Index child boy Younger sibling girl

\begin{tabular}{ccccccc|cccccccc}
\hline $\mathbf{n}$ & mean & SD & n & mean & SD & $\boldsymbol{p}^{*}$ & $\mathbf{n}$ & mean & SD & n & mean & SD & $\boldsymbol{p}^{*}$ \\
& & & & & & & & & & & & & & \\
15 & 17.5 & 2.556 & 17 & 16.3 & 1.560 & 0.136 & 15 & 16.2 & 1.307 & 16 & 17.8 & 1.946 & 0.013 \\
15 & 0.4778 & 1.373 & 17 & -0.213 & 0.838 & 0.136 & 15 & -0.247 & 0.702 & 16 & 0.614 & 1.046 & 0.013
\end{tabular}

Children of mothers with $G W G<7 \mathrm{~kg}^{* *}$

BMI at 5 y of age

ZBMI at $5 \mathrm{y}$ of age

1.274

$0.105 \mid 10$

10.5

\begin{tabular}{ccccccc|ccccccc}
5 & 17.4 & 2.522 & 6 & 16.8 & 2.007 & 0.715 & 4 & 15.5 & 0.770 & 5 & 17.0 & 1.522 & 0.86 \\
5 & 0.412 & 1.355 & 6 & 0.069 & 1.078 & 0.715 & 4 & -0.628 & 0.414 & 5 & 0.188 & 0.817 & 0.86
\end{tabular}

\section{Control group}

\section{All children}

BMI at 5 y of age

ZBMI at 5 y of age $\begin{array}{lllll}15 & 16.4 & 1.240 & 14 & 17.9\end{array}$

$\begin{array}{lllll}15 & -0.142 & 0.666 & 14 & 0.659\end{array}$ \begin{tabular}{ll|l}
2.930 & 0.239 & 18
\end{tabular}

$1.574 \quad 0.239$

$\begin{array}{lll}16.8 & 1.403 & 17\end{array}$

0.063

$0.754 \quad 17$

17

16.9

0.1286

1.792

$\begin{array}{ll}0.963 & 0.792\end{array}$

\section{Children of mothers with $G W G>7 \mathrm{~kg}^{* *}$}

$\mathrm{BMI}$ at $5 \mathrm{y}$ of age

ZBMI at 5 y of age

$\begin{array}{lllll}9 & 16.7 & 1.292 & 9 & 18.2\end{array}$

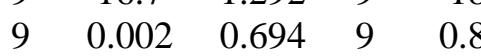

\section{Children of mothers with $G W G<7 \mathrm{~kg}^{* *}$}

BMI at 5 y of age

ZBMI at 5 y of age

\begin{tabular}{lllllll|ll}
3 & 16.7 & 1.050 & 3 & 18.195 & 3.687 & 0.827 & 1 & 18.7
\end{tabular}

\begin{tabular}{ll|lllllll}
3.090 & 0.270 & 15 & 16.6 & 1.422 & 15 & 16.9 & 1.906 & 0.852
\end{tabular}

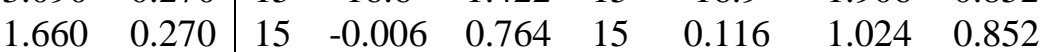

* Mann-Whitney U Test ** Index pregnancy. Only women with simplex pregnancies are included. Weight registered in the same week as the delivery. If this value was missing, the weight was measured 1 or 2 weeks before the delivery 
Table 3b. Body Mass Index (BMI) and standard score of Body Mass Index (ZBMI) for index girls and their younger siblings in the intervention- and control group at 5 years (y) of age and in relation to gestational weight gain (GWG) in the index pregnancy

\section{Intervention group}

\section{All children}

BMI at $5 \mathrm{y}$ of age

ZBMI at $5 \mathrm{y}$ of age

\section{Girls}

\begin{tabular}{|c|c|c|c|c|c|c|c|c|c|c|c|c|c|}
\hline \multicolumn{3}{|c|}{ Index child girl } & \multicolumn{3}{|c|}{ Younger sibling boy } & \multicolumn{4}{|c|}{ Index child girl } & \multicolumn{3}{|c|}{ Younger sibling girl } & \multirow[b]{2}{*}{$p^{*}$} \\
\hline $\mathbf{n}$ & mean & SD & $\mathbf{n}$ & mean & SD & $p^{*}$ & $\mathbf{n}$ & mean & SD & $\mathbf{n}$ & mean & SD & \\
\hline 23 & & & 2 & & & & 1 & & 2.2 & & & ? & \\
\hline 23 & -0.164 & 0.879 & 23 & -0.271 & 0.728 & 0.341 & 13 & 0.247 & 1.197 & 13 & 0.238 & 1.310 & 0.682 \\
\hline
\end{tabular}

\section{Children of mothers with $G W G \geq 7 \mathrm{~kg}^{* *}$}

BMI at 5 y of age

ZBMI at $5 \mathrm{y}$ of age

\begin{tabular}{lllllll|lllllll}
14 & 16.3 & 1.716 & 14 & 16.1 & 1.204 & 0.963 & 6 & 17.2 & 3.193 & 6 & 17.5 & 2.501 & 0.631 \\
14 & -0.185 & 0.922 & 14 & -0.274 & 0.647 & 0.963 & 6 & 0.315 & 1.715 & 6 & 0.470 & 1343 & 0.631
\end{tabular}

Children of mothers with $G W G<7 \mathrm{~kg}^{* *}$

BMI at 5 y of age

ZBMI at 5 y of age

\begin{tabular}{ccccccc|ccccccc}
8 & 16.7 & 1.489 & 8 & 16.5 & 1.401 & 0.600 & 5 & 17.2 & 1.380 & 5 & 15.6 & 1.080 & 0.047
\end{tabular}

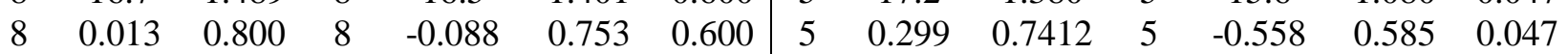

\section{Control group}

\section{All children}

BMI at 5 y of age

ZBMI at 5 y of age

$\begin{array}{cccc}16 & 16.0 & 1.337 & 16 \\ 16 & -0.371 & 0.718 & 16\end{array}$

16.3

\begin{tabular}{ll|ll}
1.391 & 0.451 & 17 & 15.9
\end{tabular}

1.288

$\begin{array}{ll}17 & 16.2\end{array}$

$1.879 \quad 0.642$

Children of mothers with $G W G \geq 7 \mathrm{~kg}^{* *}$

$\mathrm{BMI}$ at $5 \mathrm{y}$ of age

ZBMI at 5 y of age $\begin{array}{llll}9 & 16.4 & 1.370 & 9\end{array}$

$\begin{array}{llll}9 & -0.129 & 0.736 & 9\end{array}$
16.2

$-0.234$ \begin{tabular}{ll|ll}
0.909 & 0.825 & 12 & 15.6
\end{tabular}

\begin{tabular}{ll|ll}
0.488 & 0.825 & 12 & -0.558
\end{tabular}
1.109

0.596
Children of mothers with $G W G<7 \mathrm{~kg}^{* *}$

BMI at 5 y of age

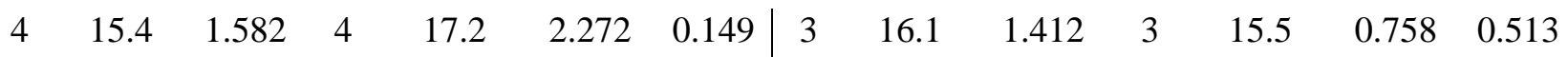

ZBMI at 5 y of age

$4 \quad-0.657 \quad 0.850 \quad 4$

* Mann-Whitney U Test ** Index pregnancy. Only women with simplex pregnancies are included. Weight registered in the same week as the delivery. If this value was missing, the weight was measured 1 or 2 weeks before the delivery 
Table 4. Comparison of mean Body Mass Index at 5 years of age between younger siblings in the intervention- and control group

\begin{tabular}{|l|l|l|l|}
\hline & Intervention group & Control group & p-value* \\
\hline \multirow{3}{*}{ Index child boy } & & & \\
\cline { 2 - 4 } & Younger sibling boy & Younger sibling boy & 0.131 \\
\cline { 2 - 4 } & Younger sibling girl & Younger sibling girl & 0.150 \\
\hline & & & \\
\hline \multirow{3}{*}{ Index child girl } & & & \\
\cline { 2 - 4 } & Younger sibling boy & Younger sibling boy & 0.932 \\
\cline { 2 - 4 } & Younger sibling girl & Younger sibling girl & 0.490 \\
\hline & & & \\
\hline
\end{tabular}

* Mann-Whitney U test 
Table 5. Distributions of Body Mass Index values among index children and their younger siblings in the intervention- and control group at 5 years of age According to Body Mass Index reference values (mean and SD) for Swedish children*

\section{Intervention group}

\begin{tabular}{|c|c|c|c|c|c|c|c|c|c|c|c|c|c|c|c|c|c|c|c|c|c|}
\hline \multicolumn{11}{|c|}{ Boys } & \multicolumn{11}{|c|}{ Girls } \\
\hline & \multicolumn{2}{|c|}{$\begin{array}{c}\text { Index child } \\
\text { boy }\end{array}$} & \multicolumn{2}{|c|}{$\begin{array}{c}\text { Younger } \\
\text { sibling boy }\end{array}$} & \multicolumn{3}{|c|}{$\begin{array}{c}\text { Index child } \\
\text { boy } \\
\end{array}$} & \multicolumn{2}{|c|}{$\begin{array}{c}\text { Younger } \\
\text { sibling girl }\end{array}$} & \multirow[b]{2}{*}{$p^{* *}$} & & \multicolumn{2}{|c|}{$\begin{array}{c}\text { Index child } \\
\text { girl }\end{array}$} & \multicolumn{2}{|c|}{$\begin{array}{c}\text { Younger } \\
\text { sibling boy }\end{array}$} & \multicolumn{3}{|c|}{$\begin{array}{c}\text { Index child } \\
\text { girl }\end{array}$} & \multicolumn{2}{|c|}{$\begin{array}{c}\text { Younger } \\
\text { sibling girl }\end{array}$} & \multirow[b]{2}{*}{$p^{* *}$} \\
\hline & $\mathrm{n}$ & $\%$ & $\mathrm{n}$ & $\%$ & $p^{* *}$ & $\mathrm{n}$ & $\%$ & $\mathrm{n}$ & $\%$ & & & $\mathrm{n}$ & $\%$ & $\mathrm{n}$ & $\%$ & $p^{* *}$ & $\mathrm{n}$ & $\%$ & $\mathrm{n}$ & $\%$ & \\
\hline & & & & & 0.321 & & & & & 0.098 & & & & & & 1.000 & & & & & 0.926 \\
\hline $\begin{array}{l}+3 \\
\mathrm{SD}\end{array}$ & 3 & 20.0 & 0 & 0.0 & & 0 & 0.0 & 1 & 6.3 & & $\begin{array}{l}+3 \\
\text { SD }\end{array}$ & 0 & 0.0 & 0 & 0.0 & & 1 & 7.7 & 1 & 7.7 & \\
\hline $\begin{array}{l}+2 \\
\text { SD }\end{array}$ & 1 & 6.7 & 1 & 5.9 & & 1 & 6.7 & 4 & 25.0 & & $\begin{array}{l}+2 \\
\text { SD }\end{array}$ & 2 & 8.7 & 1 & 4.3 & & 1 & 7.7 & 2 & 15.4 & \\
\hline $\begin{array}{l}+1 \\
\mathrm{SD}\end{array}$ & 3 & 20.0 & 3 & 17.6 & & 2 & 13.3 & 5 & 31.3 & & $\begin{array}{l}+1 \\
\text { SD }\end{array}$ & 5 & 21.7 & 4 & 17.4 & & 3 & 23.1 & 3 & 23.1 & \\
\hline Mean & 7 & 46.7 & 9 & 52.9 & & 12 & 80.0 & 6 & 37.5 & & Mean & 14 & 60.9 & 15 & 65.2 & & 8 & 61.5 & 7 & 53.8 & \\
\hline$-1 \mathrm{SD}$ & 1 & 6.7 & 4 & 23.5 & & 0 & 0.0 & 0 & 0.0 & & $-1 \mathrm{SD}$ & 2 & 8.7 & 2 & 8.7 & & 0 & 0.0 & 0 & 0.0 & \\
\hline$-2 \mathrm{SD}$ & 0 & 0.0 & 0 & 0.0 & & 0 & 0.0 & 0 & 0.0 & & $-2 \mathrm{SD}$ & 0 & 0.0 & 1 & 4.3 & & 0 & 0.0 & 0 & 0.0 & \\
\hline$-3 \mathrm{SD}$ & 0 & 0.0 & 0 & 0.0 & & 0 & 0.0 & 0 & 0.0 & & $-3 \mathrm{SD}$ & 0 & 0.0 & 0 & 0.0 & & 0 & 0.0 & 0 & 0.0 & \\
\hline
\end{tabular}

\section{Control group}

\begin{tabular}{|c|c|c|c|c|c|c|c|c|c|c|c|c|c|c|c|c|c|c|c|c|c|}
\hline \multicolumn{11}{|c|}{ Boys } & \multicolumn{11}{|c|}{ Girls } \\
\hline & \multicolumn{2}{|c|}{$\begin{array}{c}\text { Index child } \\
\text { boy } \\
\end{array}$} & \multicolumn{2}{|c|}{$\begin{array}{c}\text { Younger } \\
\text { sibling boy }\end{array}$} & \multicolumn{3}{|c|}{$\begin{array}{c}\text { Index child } \\
\text { boy } \\
\end{array}$} & \multicolumn{2}{|c|}{$\begin{array}{c}\text { Younger } \\
\text { sibling girl } \\
\end{array}$} & \multirow[b]{2}{*}{$p^{* *}$} & & \multicolumn{2}{|c|}{$\begin{array}{c}\text { Index child } \\
\text { girl }\end{array}$} & \multicolumn{2}{|c|}{$\begin{array}{c}\text { Younger } \\
\text { sibling boy }\end{array}$} & \multicolumn{3}{|c|}{$\begin{array}{c}\text { Index child } \\
\text { girl }\end{array}$} & \multicolumn{2}{|c|}{$\begin{array}{c}\text { Younger } \\
\text { sibling girl }\end{array}$} & \multirow[b]{2}{*}{$p^{* *}$} \\
\hline & $\mathrm{n}$ & $\%$ & $\mathrm{n}$ & $\%$ & $p^{* *}$ & $\mathrm{n}$ & $\%$ & $\mathrm{n}$ & $\%$ & & & $\mathrm{n}$ & $\%$ & $\mathrm{n}$ & $\%$ & $p^{* *}$ & $\mathrm{n}$ & $\%$ & $\mathrm{n}$ & $\%$ & \\
\hline & & & & & 0.172 & & & & & 0.423 & & & & & & 0.373 & & & & & 0.755 \\
\hline $\begin{array}{l}+3 \\
\text { SD }\end{array}$ & 0 & 0.0 & 4 & 28.6 & & 0 & 0.0 & 1 & 5.9 & & $\begin{array}{l}+3 \\
\mathrm{SD}\end{array}$ & 0 & 0.0 & 1 & 6.3 & & 0 & 0.0 & 1 & 5.9 & \\
\hline+2 & 1 & 6.7 & 0 & 0.0 & & 2 & 11.1 & 2 & 11.8 & & +2 & 0 & 0.0 & 0 & 0.0 & & 0 & 0.0 & 0 & 0.0 & \\
\hline
\end{tabular}




\begin{tabular}{|c|c|c|c|c|c|c|c|c|c|c|c|c|c|c|c|c|c|}
\hline $\begin{array}{l}\text { SD } \\
+1 \\
\text { SD }\end{array}$ & 4 & 26.7 & 2 & 14.3 & 7 & 38.9 & 4 & 23.5 & $\begin{array}{l}\text { SD } \\
+1 \\
\text { SD }\end{array}$ & 5 & 31.3 & 3 & 18.8 & 4 & 23.5 & 2 & 11.8 \\
\hline Mean & 9 & 60.0 & 7 & 50.0 & 7 & 38.9 & 10 & 58.8 & Mean & 10 & 62.5 & 12 & 75.0 & 12 & 70.6 & 13 & 76.5 \\
\hline$-1 \mathrm{SD}$ & 1 & 6.7 & 1 & 7.1 & 2 & 11.1 & 0 & 0.0 & $-1 \mathrm{SD}$ & 1 & 6.3 & 0 & 0.0 & 1 & 5.9 & 1 & 5.9 \\
\hline$-2 \mathrm{SD}$ & 0 & 0.0 & 0 & 0.0 & 0 & 0.0 & 0 & 0.0 & $-2 \mathrm{SD}$ & 0 & 0.0 & 0 & 0.0 & 0 & 0.0 & 0 & 0.0 \\
\hline $3 \mathrm{SD}$ & 0 & 0.0 & 0 & 0.0 & 0 & 0.0 & 0 & 0.0 & $-3 \mathrm{SD}$ & 0 & 0.0 & 0 & 0.0 & 0 & 0.0 & 0 & 0.0 \\
\hline
\end{tabular}

* +3SD +2SD +1SD Mean -1 SD $\quad$-2SD $\quad$-3SD

$\begin{array}{llllllll}\text { Boy } & 20.341 & 18.522 & 17.024 & 15.766 & 14.694 & 13.769 & 12.961\end{array}$

$\begin{array}{llllllll}\text { Girl } & 21.154 & 18.720 & 16.897 & 15.472 & 14.320 & 13.366 & 12.561\end{array}$

** Fischer’s Exact test 
Table 6. Comparison of Body Mass Index values (according to reference values for Swedish children) between younger siblings in the intervention- and control group at 5 years of age

\begin{tabular}{|l|l|l|l|}
\hline & Intervention group & Control group & p-value* \\
\hline \multirow{3}{*}{ Index child boy } & & & \\
\cline { 2 - 4 } & Younger sibling boy & Younger sibling boy & 0.151 \\
\cline { 2 - 4 } & Younger sibling girl & Younger sibling girl & 0.691 \\
\hline & & & \\
\hline \multirow{3}{*}{ Index child girl } & & & \\
\cline { 2 - 4 } & Younger sibling boy & Younger sibling boy & 0.772 \\
\cline { 2 - 4 } & Younger sibling girl & Younger sibling girl & 0.343 \\
\hline & & & \\
\hline
\end{tabular}

* Fischer's Exact test 